\title{
Contributions of HIVIAIDS Social Networking Sites towards Awareness and Prevention of the Pandemic among Students of Rhodes University, South Africa
}

\author{
Nkosinothando Mpofu \\ Department of Communication \\ University of Fort Hare, South Africa \\ Professor Abiodun Salawu \\ Department of Communication, North-West University \\ Mafikeng Campus, Mmabatho 2735, South Africa
}

Doi:10.5901/mjss.2014.v5n6p191

Abstract

Social networking sites (SNSs) have gained remarkable acceptance in South Africa as platforms for social communication. The increase in platforms or spheres through which SNSs can be accessed has contributed to the growth in numbers of users both in the rural and urban settings. Although this increase in use covers various age groups, young people remain at the forefront of embracing the SNSS. Owing to their popularity and potential, SNSs have since ceased to be platforms only for social communication but have also now been used for more beneficial purposes such as education and health communication. This article thus explores how one SNS (MYMsta.mobi) focussing on HIVIAIDS related issues is being used by young people in South Africa, who in this case are represented by Rhodes University students, with the intent of unveiling the consequences of using such sites towards increasing knowledge on HIVIAIDS and supporting the adoption of preventive efforts. Drawing from a quantitative survey and the use of open-structured questions with Rhodes students, this article argues that when strategically designed and implemented, HIVIAIDS social networking sites can become significant tools towards reinforcing and increasing knowledge about HIVIAIDS which is an essential element towards the adoption of preventive behaviours among young people in South Africa.

Keywords: HIVIAIDS, Youths, Social Network Sites, MYMsta.mobi, Rhodes Students, HIVIAIDS Communications

\section{Introduction}

Sub-Saharan Africa constitutes a greater percentage of the youths infected by the epidemic in the world. There were approximately 2.7 million infected youths in sub-Saharan Africa at the end of 2009 (UNICEF, 2010); indicating the need for more rigorous efforts to curb the growth of new infections. In South Africa, a country that already has one of the highest HIV figures in the world; young people constitute a significant percentage of the total number of people living with HIV. As of 2008, the HIV prevalence amongst the youth in South Africa was approximately $9 \%$, with female youths being the most affected (Setswe, 2009). Two and a half percent of males in the age group of 15-19 were infected as compared to $6.5 \%$ females in the same age group whilst $5.1 \%$ males in the age group of $20-24$ were infected when compared to the 21. 1\% females in the same age group in 2008 (Setswe, 2009). According to the Reproductive Health Research Unit (RHRU), the peak of HIV incidence occurs in young people aged between 15-24 year old and it further states that half of all adults who acquire HIV become infected before they turn 25; a clear indicator of the manner in which HIV is affecting the youth in South Africa. Because of the extent to which HIVIAIDS is affecting young people, mobilizing more channels to communicate with can aid significantly in increasing exposure to HIVIAIDS communication which has the potential to persuade young people towards adopting preventive behaviours against HIVIAIDS.

The use of the internet and its applications for health information purposes is on the rise with studies showing the internet as one of the most widely used resource for health information. Further the emerging social media such as online forums, message boards and health related social networking sites have received immense attention from health information seekers. According to Elkin (2008) approximately one third of online health information seekers have used social media resources and this number is expected to grow as more and more people seek information and help from their peers (Fox \& Jones, 2009). Social media, in particular health related social networking sites, can provide a venue through which people can connect with others, exchange information and sharing experiences (ibid). 
Health social networking sites have the potential to amplify the speed and ease with which information is communicated as well as enabling interactive communication flows within networks. Although not yet many in number, current health related social sites have harnessed this platform to communicate health messages and support societal participation in issues concerning their health (AIDS.gov, 2008). Crucial to these sites are the opportunities for dialogue that emanate from the use of social sites. For example, many people make sense of information when they are able to discuss and debate it and for social change to occur there must be opportunities for dialogue (Figueroa et al, 2002). Figueroa et al (2002) further state that when information helps people communicate, participate and make informed choices, it is only then that the information becomes beneficial. Participation is critical if development/change is to occur, hence health related social sites are seen as having much potential in communicating about HIVIAIDS as they can allow people to discuss and debate issues of concern, enabling them to make informed choices.

MYMsta.mobi is one such example of a social networking initiative that has been developed to communicate with young people on HIVIAIDS related issues. It has been developed in a manner that allows users to learn and share opinions and experiences on HIVIAIDS issues. This study focuses on MYMsta.mobi in order to assess the contributions of HIVIAIDS social sites in increasing awareness and fostering prevention among young people, who in this case are represented by Rhodes university students. Using the uses and gratifications perspective, this study seeks to answer the question: Does MYMsta.mobi have appreciable effects on HIVIAIDS awareness and prevention among Rhodes University students? This is done by focussing on the following sub-questions: what are uses of MYMsta.mobi amongst students and what are the motivation of those uses as well as the impact of using MYMsta.mobi on HIVIAIDS awareness and prevention. Adopting this approach will provide an understanding over the nature and scope of contributions experienced as a result of using health social sites such as MYMsta.mobi.

\section{Usage of HIVIAIDS Social Networking Sites}

The growing numbers of people using online resources for health information has led to the establishment of more health communication platforms and even some organisations tapping into the potential of popular social sites to address health concerns like HIVIAIDS. According to Fox \& Jones (2009), results on a study about the social life of health information, show that 39 percent of users look online for health information and use a social networking site of some kind. This raises the need to integrate social networking sites into the broader framework of health communication.

Health-focused social networks, in particular HIVIAIDS social networking sites, function as communities for people with specific medical conditions or concerns and provide space for users to share their experiences, find support and discuss their health concerns and treatment information with others (AIDS.gov, 2008). In summary, AIDS.gov (2008) maintains that the purpose of HIVIAIDS social networking sites is to:

- Connect people around HIV prevention, testing, treatment and research information

- Form support groups for those living with and affected by HIVIAIDS and,

- Find and share information about HIVIAIDS related events or activities.

Online health enquiries have had an impact on decisions or actions of recipients and there are clearly more positive experiences than negative ones (Fox \& Jones, 2009). For example a study conducted by Pew Internet \& American Life project revealed that 60 percent of the participants found online health information which affected their decision about how to treat or manage an illness whilst 56 percent maintained that online health information changed their overall approach to maintaining their health and that of others (Fox \& Jones, 2009).

Health initiatives designed for social network sites have been implemented in developed countries with results showing some positive remarks from users. A study conducted in the USA on the social life of health information showed that 39 percent of users look online for health information and use a social networking site of some kind to get health information (Elkin, 2008). In the same study, among those once diagnosed as having a serious health condition, about thirty percent reported that they have found online communities dedicated to their health issues (Annenberg National Health Communication Survey, 2008). This experience of developed nations can also be realised in the African context where effective strategies are designed in line with access levels and technological abilities of targeted populations.

Although there has been a sparing use of social sites, more research has to be conducted to validate their potential in fighting social ills within societies, given the huge numbers of people using social sites. Of particular interest, understanding the role social sites can play in addressing issues of HIVIAIDS amongst the youth becomes critical as there are at the fore front in embracing and using social network sites. According to Anderson (2011) one way to maximize the effect of any prevention intervention programme is to 'fish where the fish is'. Fox \& Jones (2009) further asserts that as younger adults face more health care questions and challenges, they may turn to the tools that they have sharpened in other contexts of their lives to gather and share health advice. 
Examples of HIVIAIDS social networking sites include amongst others, AIDS.gov on Facebook and MySpace, CDC on Facebook and MySpace and PEPFAR on Facebook. In South Africa, MYMsta.mobi is one example of an HIVIAIDS social networking site developed for young people in order for them to hold dialogues on HIVIAIDS and its related issues with their peers. Below is a description of the MYMsta social network site.

\section{MYMsta.mobi Initiative}

MYMsta is an abbreviation for Make Your Move: a mobile social network, by and for the youth, dedicated towards the empowerment and prevention of HIVIAIDS amongst young people in South Africa (Seopa, 2008). MYMsta seeks to reach out to young people by giving them a platform in which they can discuss with others, issues that are of concern and probably come up with solutions to the problems faced by young people today (DasGupta, 2008). This initiative was established and launched in June 2008 by Love Life and Trina DasGupta; becoming the first mobile social network in the world to tackle HIVIAIDS related issues (Seopa, 2008).

MYMsta stems from the Love life's belief that it is the circumstances of the young people and not their disregard for HIV prevention that continues to drive the epidemic (DasGupta, 2008). Thus MYMsta strives to address the social determinants of HIV through giving young people access to knowledge, skills and opportunities that will help protect them from HIVIAIDS (Seopa, 2008). More so, by bringing together South Africa's youths, self expression, dialogue and connection of young people together will be promoted to support behavior change that is likely to occur when young people have a sense of belonging, identity and purpose (DasGupta, 2008).

MYMsta.mobi has a number of features that support different activities for users. Most of the activities support discussions on various issues that could have an impact on the well being of individuals. These activities provide young people with many reasons to protect themselves from HIV infections and these include amongst others:

- Nakanjani: this feature allows users to share their experiences and engagement in activities that seek to empower them and community members at large

- Foxy Chix: presents 60 second soap operas in which foxy chix is depicted as facing dilemmas as well as providing ways in which those dilemmas can be solved. This feature allows users to discuss and post their views regarding issues discussed in the soapies.

- Relationships: this feature allows users to discuss any issue regarding relationships. Questions on how to handle certain relationship situations can be discussed with advice given on how to handle or manage certain problems in relationships.

- Employment: this feature allows users to discuss the challenges that come with high unemployment rates in South Africa and how to overcome those challenges.

- Do it yourself: this feature allows users to discuss and show how they handle situations when under pressure.

- General: the general feature allows users to raise and discuss any issues of interest and concern.

Because of the sensitive nature of some issues discussed and the need to support an exchange of accurate information among users, MYMsta.mobi has a regulator that will monitor the discussion on MYMsta with minimal interference. Basically the purpose of MYMsta is to provide a platform where young people can address their concerns with their peers. It is this exchange of informational resources that allow for the transfer of social influence which can influence protective behaviours in all circumstances.

\section{Usage of Social Networking Sites amongst the Youth}

According to the World youth report (2005), one area where young people have an edge is the emergent society, which is driven by new technologies. Globally, more and more young people are using the Internet and its products, regardless of existing disparities in terms of access. Different usage trends related to the Internet have also been noted amongst youth in developing and developed countries. However, such disparities have not nullified the fact that young people are at the forefront in embracing the Internet and other technological products aimed at them. For the purpose of this study, the trends of social network use are briefly discussed in terms of the current number of users and the purpose of their use.

Rapid technological developments have made a significant contribution to the rise and use of online social networking sites. In a study conducted on the use of social networks amongst American teenagers, Tucker (2009) notes that 51 per cent of teenagers in America check their social networking sites more than once a day, whilst 22 per cent check more than ten times a day. In South Africa, social sites such as MXit draw approximately 14.5 million users, with 
most users accessing the site daily (ClubbersGuide 2010). Globally, Facebook has over 200 million users; the youth contribute the greatest proportion of this number (Reuters 2009). In a study conducted by World Wide Worx and Fuseware (2012) on the use of social media in South Africa, results indicated a growing use of social networking sites among rural and urban dwellers and across different age groups. This study further shows that by August 2012 there approximately 5.33 million people (South Africans) who were accessing Facebook through the web while 6.8 accessing Facebook through mobile phones (Worx \& Fuseware, 2012). For other social network sites like Twitter, MXit and Linkedln, the number of people using them were 2.43 million, 9.35 million and 1.96 million respectively (ibid).

According to Rosen (2010), Facebook forms the largest 'country' in the world, with 80 per cent of a teenager's time being spent on social networking. Rosen (ibid.) further maintains that the time youths spend on social sites is used to explore their identity, determine their personality, and find who they are. These three goals are triggers of behaviour change amongst social network members (DasGupta 2008). The time spent on social networks and the nature of information shared amongst network members can contribute to attitude change towards an object or issue. Clearly, the extents to which social networking sites are being used by the youth indicate the need to mobilize them for other beneficial purposes like health communication.

\section{Approaches to Communication}

The need to use social network sites for HIVIAIDS communication is influenced by the different approaches to communication which are described below. It is these approaches that have contributed significantly to the success of communication intervention initiatives. The use of social network sites for health communication moves away from the principles of the early paradigm to development in which development was considered to be a linear, cumulative, evolutionary and unidirectional process, through which 'experts' disseminated information they regarded as necessary to the development of communities (Melkote, 1991).

In adhering to the principles of this (early) paradigm, communication approaches attributed an overwhelming influence to communication and the media, as they were seen as primary instruments needed to achieve and maintain change (Melkote, 1991). Messages envisaged by experts as necessary for development were disseminated to the receiver in a top down manner, with the receiver considered passive and at the mercy of the media (Melkote, 1991). Because audiences are not passive as this paradigm maintains, the significant criticism levelled against this paradigm led to the development of the 'alternative paradigm'. This paradigm allowed communication approaches to recognise the importance of participation and empowerment, if any change or development was to be achieved. Audiences were thus seen as active agents of their own development because, in instances in which media were used, messages were to originate from the people rather than the experts (Mody 1991). The alternative paradigm to development thus places significant emphasis on participation as a crucial component to the success of any intervention program in influencing change amongst recipients.

Development communication, as supported by the alternative paradigm to development, has seen a shift from communication informed by individual level theories to more multilevel, cultural and contextual interventions and explanations (McKinlay and Marceau 1999). This shift seeks to ascertain the role of socio-cultural and environmental influences in shaping behaviour; an understanding that is crucial to the success of HIVIAIDS communication programmes. Socio-cultural and environmental influences permeate and affect decision making in the context of HIVIAids (Singhal 2000) and thus communication approaches appreciate that individual behaviour is embedded in social and cultural contexts.

It is clear therefore that involving people in the processes of their own development, and understanding the influence of their socio-cultural contexts, are critical for the success of any initiative. Furthermore the use of interactive and participative communication channels can also contribute to sustainable change amongst users, hence the need to use and evaluate the effect of using social networking sites for HIVIAIDS communication. According to Wasserman and Galaskiewicz (1994) social networks can support the flow of resources and influence within networks. As such, social networking sites present a platform in which learning can take place. They present an environment in which influence can be passed amongst network members. In other words, social networks have the capacity to transfer influence where informational resources on attitude and behaviour are shared (Kumar, Anagnostopoulos and Mahdian 2008). Social networks can also allow their target population to participate in their own development with regard to HIVIAIDS. As such, it becomes imperative to evaluate the contribution of HIVIAIDS social networking sites in supporting attitude change against HIVIAIDS amongst youths who are more vulnerable to the disease, and who are at the forefront of using social networks. 


\section{The Social Network Effect}

Social Networks, whether offline or online, have the capacity of transferring social influence when information about attitudes or behaviours is shared between actors in network (Kumar, et al, 2008). As maintained by the Social Network Theory, the importance of relationships in passing on influence cannot be overstated. The social network theory states that social networks provide a social environment that can influence and shape the behaviour of individuals. Thus the theory sees:

- Actors and their actions as interdependent rather than independent, autonomous units

- Relational ties (linkages) between actors as channels for transfer or "flow" of resources (either material or nonmaterial)

- The network structural environment as providing opportunities for or constraints on individual action

- Network models conceptualize structure (social, economic and political) as lasting patterns of relations among actors (Wasserman \& Faust, 2004)

The concept of social influence within the network is further explained by Buhler \& Kohler (2002) as he maintains that the structure of a network can influence people 's behaviour and beliefs. In saying so, Buhler identifies two structural features that are important towards the passing of social influence within networks; namely structural similarity and cohesiveness (Buhler \& Kohler, 2002). Cohesive networks maintain that individuals are influential because they are highly connected to one another, either directly or indirectly and there are basically two central mechanisms of network influence of behavioural change (Montgomery \& Casterline, 1996). These are social learning and social norms. Social learning maintains that influencing behaviour is based on information, evaluation and experiences made and provided by network members (Montgomery \& Casterline, 1996). According to Montgomery and Casterline (1996), social learning hastens the acquisition of new behaviours in social networks when members learn and adapt to new behaviours based on the information received and evaluated from peers. Close and highly connected peers are likely to exert an influence amongst each other through interpersonal communication.

Social norms, on the other hand, maintain that the behavioural experiences of network members have a contribution towards individual behavioural change (Montgomery\& Casterline, 1996). Human behaviour is influenced both by norms or values of a society and the perceived norms of a social network can therefore directly or indirectly influence individual behaviour (Latkin \& Doney-Rothwell, 2007). Belonging to a network or group will bear significantly on individual behaviour as norms of a network indicate the established and approved ways of doing things (Latkin \& Doney-Rothwell, 2007). In trying to be accepted, behaviour is changed in order to suit the norms of the network; hence thinking and behaviour are largely influenced by friends and others whom we have regular contact with.

Unlike cohesive networks that look at influence passed from one individual to the other as a result of their high connectedness, structural similarity looks at how influence is passed on amongst people in similar positions within the network (Buhler \& Kohler, 2002). According to Burt (1982), individuals are influenced by other occupying the same position in their social structure. Although individuals may share similar positions, they are usually not close ties or highly connected to each other. Thus structural similarity describes a scenario in which two people identically positioned in the influential communication flow use each other as a frame of reference for subjective judgement (Burt, 1982). This leads them to making similar decisions even if they have no direct communication with each other. Structurally similar individuals are able to mimic each other's behaviour as they provide each other with information regarding appropriate behaviour (Burt, 1982). Structural similarity and cohesiveness basically describe mechanisms through which influence can be passed on among members in a social network.

\section{Theoretical Framework}

This study is rooted within the broad theoretical framework of the Uses and Gratifications Theory. The theory has its roots in the 1940s, when researchers became interested in why people engage in various forms of media behaviour (Lazersfeld and Stanton 1949). The theory seeks to understand why individuals use and choose certain media in the way they do, which makes it different from the traditional effects approach (which views media users as passive, without the ability to choose). The importance of the Uses and Gratifications Theory lies in its ability to focus on the interaction of media users and the media when trying to understand media uses. As such it is able to produce abundant research on the ways in which humans interact with the media (Windahl in Ruggiero 2000).

The theory also postulates that the gratifications sought and obtained from selected media have largely contributed to the way media consumers interact with the various media. Therefore, the application of the Uses and Gratifications 
Theory to improve our understanding of the use pattern of social network sites amongst the youth in South Africa, becomes legitimate.

According to Katz et al. (1974) there are five basic assumptions of the Uses and Gratifications Theory. Three assumptions are relevant for this work:

- Communication behaviour, including media selection and use, is goal directed, purposive and motivated. Patterns of media use are shaped by more or less definite expectations of what certain kinds of media have to offer users;

- People take the initiative in selecting and using communication vehicles to satisfy felt needs and desires. Instead of being used by the media, people use and select media to gratify their needs and wants;

- Social and psychological factors mediate people's communication behaviour. Predisposition, interaction and environment mold people's expectations of the media. People's behaviour is a response to media or messages, as filtered through social and psychological circumstances (such as the potential for interpersonal interaction, social categories and psychological circumstances).

As new technologies present people with more and more choices, it becomes necessary to decode the uses and gratifications of such communication experiences (Lin 1996). The Uses and Gratifications Theory thus offers a convincing explanation for changes in media use patterns, following the adoption of new communication technologies (Ruggiero 2000). Ruggiero (ibid.) also asserts that the timely emergence of computer-mediated communication has only bolstered the theoretical potency of the Uses and Gratification Theory, by allowing it to stimulate productive research into a proliferating telecommunications medium.

New media supports interactivity, which significantly supports the core uses and gratifications notion of active users. The new media have a number of aspects that offer a vast continuum of communication behaviours to examine (Williams, Rice and Rogers 1988). According to Ruggiero (2000), there are basically three aspects of new media to focus on:

- Interactivity, which is defined as the degree to which participants in the communication process have control over and can exchange roles in their mutual discourse (Williams et al. 1988). The Uses and Gratifications Theory can therefore be applied when examining new media use, given the interactivity aspect of the new media that supports the notion of active audiences.

- Demassification, which is defined as the control of the individual over the medium, giving the media user the ability to select from a larger menu (Williams et al. 1988). Unlike traditional mass media, new media like the Internet have selective characteristics that allow individuals to tailor messages to their needs (Ruggiero 2000). This supports another notion underlined by the Uses and Gratifications Theory, namely that people will select and choose media to satisfy their personal needs.

- Asynchroneity, on the other hand, describes a scenario in which messages can be staggered in time so that receivers of the electronic messages can read them at any time (Ruggiero 2000). In other words, new technologies allow people to interact at their convenience, as individuals can send, receive and save messages. This aspect of the new media further supports individual control of the media and allows users to use media to their own satisfaction. This confirms the postulations of the Uses and Gratifications Theory.

The Uses and Gratifications Theory therefore provides a productive method of examining Internet usage. The core purpose of the theory still remains the same: to find out why people become involved in a particular type of mediated communication, and what gratification they receive from it (Ruggiero 2000). The Uses and Gratifications Theory is relevant to this study as it will help decode the uses and gratifications obtained from the use of online social network sites, amongst the youth.

\section{Methodology}

\subsection{Participants}

For the purposes of this study, Rhodes University students were used. The use of Rhodes students for this study is appropriate as it is one of the institutions in the Eastern Cape with an innovation culture (Buckland, 2009). More so, according to Pew Project, college students represent a particularly appropriate sample through which to understand the rise of the internet in social life, given their status as "pioneers" for whom social internet use has already become frequent and mundane (Pew Project on the Internet and American Life, 2002). Both quantitative and qualitative approaches to the research design and method were used in this study to obtain information from participants. Two hundred and seventy 
questionnaire copies were randomly distributed amongst Rhodes students; with a $70 \%$ response rate. In addition, 30 respondents, from the same sample, responded to short essay questions. A stratified sampling method was employed to ensure that different segments of the population acquire sufficient representation. Fifty two percent of the students participating in the study represented female students whilst $48 \%$ represented the male participants. The age of the participants varied from 18-24.

\section{Study Measures}

\subsection{Demographics of the Participants (Rhodes student)}

To get the demographics, participants were required to provide self reports on their gender, age, internet use, access to social networking sites and awareness of HIVIAIDS social networking sites.

\subsection{Uses of MYMsta.mobi Social Networking Site}

This measure sought to establish the uses of MYMsta.mobi HIVIAIDS social networking sites among Rhodes students. The use of MYMsta.mobi and time spent on MYMsta.mobi social network site was measured. The motivations for using MYMsta.mobi were also measured.

\subsection{Impact of MYMsta.mobi social networking site in increasing HIVIAIDS awareness and prevention efforts among users}

This measure sought to understand the impact of HIVIAIDS communication activities supported within HIVIAIDS social sites such as MYMsta.mobi in increasing the knowledge base of users on HIVIAIDS and supporting the adoption of preventive efforts against HIVIAIDS among users. Challenges of using social network sites to communicate about HIVIAIDS were also measured.

\section{Data Analysis}

Frequency distribution of data was done using SPSS to provide the descriptive statistics of collected data. Grounded theory was also used to analyze qualitative data.

\section{Results and Discussion}

\subsection{Participant demographics}

Of the total of 190 students who completed the questionnaire, 52 per cent were female and 48 percent male. The age of the respondents varied from 18 to 24 . It emerged from the findings that all participants (100\%) had access to the Internet, which they each used for different purposes including social networking. The amount of time participants spent on the Internet was also measured: respondents spent an average of two hours on the Internet per day. The findings regarding access to the Internet concur with the findings of other studies, which saw an increase in Internet usage. For example, Anderson (2011) identifies a rapid rise in the use of the Internet which, in turn, has increased individuals' access to and sharing of information. Furthermore, Anderson (ibid.) notes that more than 80 per cent of people are now looking online for health information - this is indicative of the potential the Internet and its products have in addressing social challenges.

\subsection{Access and use of social network sites among youths}

This variable was measured by establishing whether respondents had access to social networking sites, the amount of time respondents spent on social sites and the nature of the social sites they visited, especially those focusing on HIV and AIDS-related issues. It was revealed that 95 per cent of the respondents have a knowledge and understanding of social networking sites and are using social sites. Five per cent indicated that they do not have knowledge of the social sites and, as such, have not used them. In terms of the time spent on social sites, 65per cent of respondents access social sites daily for an average of two hours, while 33 per cent access such sites at least twice a week. The extent to 
which youths use social sites is enormous; Boyd and Ellison (2007) maintain that social networking sites are frequently used by youths and have become part of their everyday activities.

With regard to respondents' access to social sites focusing on HIVIAIDS issues, the study shows that only 30 per cent of the respondents were aware of and had used MYMsta.mobi; with an average of 60 minutes spent on the social site at a given time. Another fifteen per cent of respondents were aware of an HIVIAIDS related social networking site called YouthNoise.com; a platform that also allows young people to discuss the different challenges they encounter with their peers. The remaining 55 per cent indicated that they had no knowledge of social network sites dealing with HIVIAIDS issues. The level of access, amongst respondents, to social network sites related to HIVIAIDS can be attributed to three possible reasons:

- A very limited number of HIVIAIDS networking sites;

- A minimal awareness of the HIVIAIDS networking sites amongst the youth; and

- A lack of adequate communication strategies to increase the visibility and awareness of HIVIAIDS-related networking sites amongst the youth.

\subsection{Uses of MYMsta.mobi}

The purpose of using MYMsta and other HIVIAIDS social networking sites and the issues or topics discussed amongst network members was investigated. Results pertaining to the use of MYMsta and social sites related to HIVIAIDS were based on the responses of participants who use MYMsta and other HIVIAIDS social sites. Based on the results, it is evident that 40 per cent used these sites to learn more about HIV/Aids, whilst 20 per cent use them to share their experiences of issues related to HIVIAIDS. These findings are consistent with the research of Subrahmanyan, Reich, Waechter and Espinoza (2008), who contend that young people use online contexts to address their developmental concerns. By promoting debates and discussions, social sites cultivate the youth's ability to tackle issues of concern, thereby increasing their awareness and building solid foundations for decision making.

The results of the study also show that some respondents (12\%) use MYMsta and HIVIAIDS related social sites like YouthNoise.com to find encouragement and support from peers with similar conditions. According to AIDS.gov (2008), the most credible source of information for most people is now 'a person like me'. Structural similarity, as stated by Buhler \& Kohler (2002), supports this notion as it maintains that individuals are influenced by others occupying the same position in their social structure. In this instance, two people identically positioned in the influential communication flow use each other as a frame of reference for subjective judgment (Burt 1982). Results also show that some respondents (8\%) use MYMsta and HIVIAIDS-related social sites to learn about self-empowerment. Self-empowerment, in this instance, refers to the different ways in which economic dependence can be alleviated amongst youths, as it makes them vulnerable to HIV. It emerged from the study that, respondents on MYMsta are exposed to career opportunities and are given a platform to discuss ways of gaining individual economic empowerment. Economic dependence marginalizes people, thereby increasing their risk of infection. According to Seopa (2008), addressing the social determinants of HIV, such as economic dependence, by giving young people access to knowledge, skills and opportunities, will help protect them from HIVIAIDS.

The focus on HIVIAIDS and other factors that contribute to the spread of HIV amongst the youth is heightened by the types of topics these social platforms support. The findings show that the topics individuals chose to discuss vary, depending on the groups they join within the network. Despite this, it is evident that the common issues which respondents discuss include drug use and addiction, sexual debut and virginity, HIV testing, general health issues and individual empowerment. Figure 1 shows the percentage of representation per issue, as discussed by networking respondents. As Figure 1 shows, 30 per cent of respondents have discussed and shared ideas regarding HIV testing. This can help individuals to make decisions about knowing their status. Eighteen per cent of the respondents have discussed sexual debut and virginity issues. Questions about when someone should become sexually active and the importance of virginity were common. Drug abuse and addiction were discussed by 22 per cent of respondents. Although the respondents seem to lack clarity in understanding the relationship between drug abuse and HIV, they believe it is still a challenge facing the youth. Empowerment (13\%) and general health issues (17\%) were also discussed. Issues relating to empowerment dealt with how individuals can manage their situations, whether they are positive or negative. 


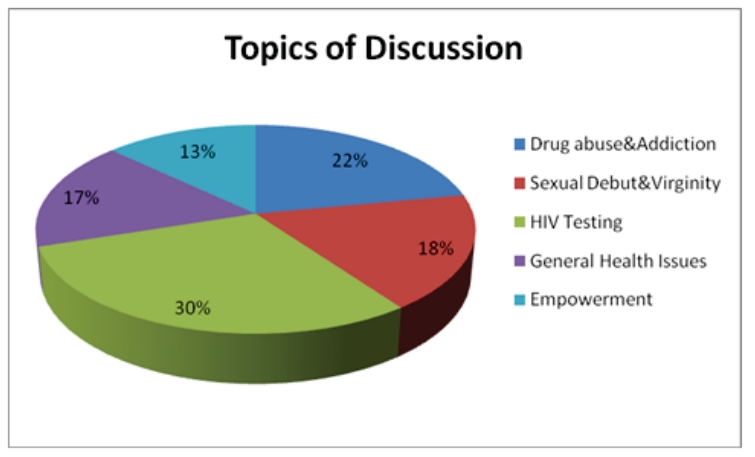

Figure 1: Topics of Discussion in HIVIAIDS Social Network Sites

Generally, respondents alluded to the fact that their discussions of the stated issues helped them realize how they can be exposed to or avoid exposure to HIV infections. These findings concur with those of Wellings et al. (1995) who conducted a study on sex education amongst young people. An analysis of the response questions on sex education showed that the majority of young people gained their sexual knowledge from friends first, then family. In other words, what they thought and believed about sex was largely a function of the social networks to which they belonged (Wellings et al., 1995). The participants' different uses of social sites are supported in the Uses and Gratifications Theory. According to Williams et al. (1988), the new media offer the media user an opportunity to select from a wider menu, which may address their needs. This process is called demassification.

\subsection{Impact of MYMsta.mobi social networking site in increasing HIVIAIDS awareness and prevention efforts among users}

The results show that by discussing various health-related issues with network members, respondents (45\%) received new and different ideas to empower them against the disease; an indicator of the role HIVIAIDS social sites can play in extending knowledge about HIV among users. The study supports the findings of Wasserman and Galaskiewicz (1994), who maintain that network ties are important as they promote the provision of and access to different kinds of information from different members: they encourage the exchange of a wider variety of (and potentially new) information between people in a network, by drawing in more peripheral communicators and extending access to wider sets of knowledge resources (Haythornthwaite 2000 in Wasserman and Galaskiewicz 1994).

It also emerged that the interactive nature of HIVIAIDS social allowed users to be involved in their own development. As discussed in relation to the Uses and Gratification Theory, interactivity which is supported within social sites affords participants control over their communication processes (Williams et al., 1988). Participation creates a sense of ownership amongst users and thereby influences the user. Ascroft and Masilela $(1994,282)$ note that 'if people do not control or share control in the processes of their own development, there can be no guarantee that it is in their best interest'. Of the respondents, 12 per cent alluded to the fact that their involvement in any important discussion creates a sense of responsibility within them and amongst those around them. This on its own can influence an individual to adopt preventive behaviour against HIVIAIDS. As such it is imperative that young people are at the centre of prevention actions, both in focus and involvement (Amuzu 2007; UNFPA 2005).

The challenges associated with the use social network sites for HIVIAIDS communication were also measured. This measure included responses from recipients who were not aware of any HIVIAIDS social network sites. The study identified three challenges, namely: type of relationships in social networks, security in social sites and the artificiality of social sites. Respondents (30 per cent) indicate that they cannot trust all network members and as such are not able to hold constructive discussions with most network members. The effect of the strength of ties is discussed by Wasserman \& Galaskiewicz (1994) who maintain that strength of ties can allow or hinder the flow of rich and detailed information on any issue, which is necessary towards the achievement of a shared understanding. Results also indicate that participants (32\%) consider the issue of privacy within social sites as a major hindrance in the discussion of issues related to HIVIAIDS amongst network members. Given the sensitive nature of issues related to HIVIAIDS, participants have shown a fear for the potential misuse of personal information in cases where privacy is not maintained. A lack of confidence in the manner in which sites protect the confidentiality of the information they provide was also highlighted. 
Artificiality within social sites is another challenge for HIVIAIDS communication on social sites. Artificiality in this context is talked about in reference to personal identity on social sites. Participants (28\%) alluded to the fact that people can post false information about themselves, making it difficult to hold discussions with new people. This becomes problematic as such scepticism may hinder the flow of beneficial information from weaker ties within the network.

HIVIAIDS social networking sites possess much potential as channels that can provide informational resources that will support a positive attitude towards HIVIAIDS amongst young people. The minimal number of respondents aware of HIVIAIDS social networking sites, in this study, affected the generalisability of the results. As such more studies must be conducted to provide additional information on the effect of HIVIAIDS social networking sites among young people. Based on the findings of the study, the following conclusions and recommendations are made.

\section{Conclusions}

Based on the research findings, it is noted that:

- Social networking sites, in general, are heavily used by young people for various activities.

- At the time of study, there was a limited or minimal use of social sites like MYMsta and YouthNoise.com focusing on addressing challenges faced by the youth. These are platforms that address various determinants of HIV infections among the youth.

- Awareness of social network sites focusing on health and HIVIAIDS related issues is minimal amongst the youth.

- Relevant and accurate information exchange can support learning and empowerment amongst network members.

- Discussions held on HIVIAIDS social sites have contributed towards an increased understanding of various aspects relating to HIVIAIDS, allowing young people to participate in the processes of their development

- The nature of discussion topics supported within MYMsta.mobi address the main factors fuelling the spread of HIVIAIDS amongst the youth; making this social platform important for HIVIAIDS communication. MYMsta.mobi has supported the increase in knowledge of HIVIAIDS among users.

- Privacy, artificiality and nature of relationships within social networking sites are seen as challenges to HIVIAIDS communication that can be implemented on the social sites.

- HIVIAIDS social network sites have the potential of becoming an important communication platform for HIVIAIDS communication when all concerns, like privacy and artificiality, regarding the use of social sites for health purposes have been addressed.

\section{Recommendations}

Recommendations will aid in the development and efficient use of social network sites for HIVIAIDS communication purposes. They include:

- Development of initiatives or strategies that will increase the visibility and knowledge of new and current social network sites focusing on HIVIAIDS and its related issues among young people. This could include putting links on the sites youth are mostly visiting. Awareness could increase the usage of these social sites.

- Design and development of attractive and user-friendly HIVIAIDS social sites that will attract and keep users at the same time achieving its goal of educating young people about HIVIAIDS.

- Identify and implement measures that can support the maintenance of relationships within networks. Maintenance of relationships builds confidence among network members and as such has a significant bearing on the quality of information exchanged amongst network members.

- Implementing policies, in the development of health social sites, which will clearly address issues of privacy and artificiality within social sites. This will create confidence amongst network members and as such support exchange of valuable information resources.

- Conduct more research on the use of social sites like MYMsta.mobi in order to generate knowledge that they improve their efficiency. 


\section{References}

Aids.gov. (2008) Health-focused Social Networking Sites. Available at http://blogs.aids.gov/2008/04/health-focused-social-networkingsites.html

Anderson, J. (2011) Future Federal Directions in Mobile Technology. Available at http://blog.aids.gov/2011/01/future-federal-directionsin-mobile-technology-in health.html

Annenberg National Health Communication Survey. 2008. ANHCS data set.

Ascroft, J. \& S. Masilela. 1994. Participatory Decision Making in Third World Development. New Delhi: Sage Publications.

Boyd, D.M \& Ellison, N.B. (2007) Social Network Sites: Definition, History and Scholarship. Journal of Computer-Mediated Communication, 13(1): article 11

Buckland, M. (2009) Rhodes University: My alma mater. Available at http://www.matthewbuckland.com/?tag=rhodes-university

Buhler, C \& Kohler, P. H. (2002) Talking About AIDS: The Influence of Communication Networks on Individual Risk Perceptions of HIVIAIDS Infection and Favoured Protective Methods in South Nyanza District, Kenya. Working Paper, WP 2002-020. Max Planck Institute for Demographic Research

Burt, R.S. (1982) Toward a Structural Theory of Action: Network Models of Social Structure, Perception and Action. New York: Academic Press

Clubbers Guide. (2010) MXit Creates Bridge Across Social Networks. Available at http://clubbersguideonline.co.za/News.aspx?i=46

DasGupta, T. (2008) The Power of Peers. NGO-Pulse, Issue 134. Web 2.0, Social Networking, Toolkit. Available at http://www.sangonet.org.za

Elkin, N. 2008. How America Searches: Health and Wellness. New York: Icrossing

Katz, E., Blumler, J., \&Gurevitch, M. 1974). Utilization of mass communication by the individual. In J.Blumler \& E. Katz (Eds.), The uses of mass communication: Current perspectives on gratifications research (pp. 19-34). Beverly Hills, CA: Sage.

Kumar, R., Anagnostopoulos, A. \& Mahdian, M. (2008) Influence and Correlation in Social Networks. Available at http://www.arnetminer.org/viewpub.do?pid=473567\#Reference

Latkin, C.A \& Doney-Rothwell, M.A. (2007) Gender Differences in Social Network Influence among Injection Drug Users: Perceived Norms and Needle Sharing. Journal of Urban Health, 84(5): pp. 691-703

Lazersfeld, P.F. \& F. Stanton. 1949. Communication Research. New York: Harper \& Row.

Lin, C.A. 1996. Personal Computer Adoption and Internet Use. Paper Presented to the Annual Convention of the Association of Education in Journalism and MassCommunication.CA: Anaheim

McKinlay, J.B. \& Marceau, L.D. (1999) A tale of 3 tails. American Journal of Public Health, 89(3): pp. 295-301

Melkote, S.R. 1991. Communication for Development in the Third World: Theory and Practice. New Delhi, India: Sage Publications.

Mody, B. (1991) Designing Messages for Development Communication. New Delhi, India: Sage Publications.

Montgomery, M.R \& Casterline, J.B. (1993) Social Learning, Social Influence and New Models of Fertility. Population and Development Review, Supplement 22: pp. 151155

Pew Project on the Internet and American Life. (2002) The Internet goes to college: How students are living in the future with today's technology. Available at http://www.pewinternet.org/reports/index.asp

Reproductive Health Research Unit (RHRU). HIV and Sexual Behaviour among Young South Africans: A National Survey of the 1524year olds. Available at http://www.rhru.co.za/content/files/documents/National_Youth_Survey_Fact_Sheet. df

Reuters. (2009) Facebook Passwords Hacked through Phishing Attack. [Online] Available: http://www.webmasterworld.com /community_building/3914424.htm

Rosen, L. (2010) Rewired: Understanding the Generation and the way they learn. [Online] Available: http://blog.discoveryeducation.com.pennsylvania/2010/09/15/dr-larryrosen rewired understanding-the-generation-and-the-waythey-learn

Ruggiero, T. E. 2000. Uses and Gratification Theory in the 21st Century. London, UK: Routledge.

Singhal, A. (2000) International Workshop UNAIDS HIVIAIDS communication for behaviour and social change; Programme Experiences, Examples and Way forward. Geneva.

Seopa, T. 2008. Love Life Generation on Mobile. [Online] Available http://www.bizcommuity.com/article/196/78/25657.html

Setswe, G. (2009) The HIV and AIDS Epidemic in South Africa: Where are we?. South Africa: HSRC

Subrahmanyan, K., Reich, S. M., Waechter, N. \& Espinoza, G. (2008) Online and Offline Social Networks: Use of Social Networking Sites by Emerging Adults. Journal of Applied Developmental Psychology, 29(6): 420-433

Tucker, J. (2009) Social Networking has hidden dangers for teens. San Francisco Chronicle. [Online] Available: http://wwwsfgate.com/cgibin/article.cgi?f=/c/a/2009/08/10/MN9 1954T7.DTL\#ixzzONndVVm04

UNICEF. (2010) Towards Universal Access: Scaling up Priority HIVIAIDS Interventions in the Health sector. [Online] Available: http://www.who.int/hiv/pub/2010progressreport/en/index.html

Wasserman, S. \& Galaskiewicz, J. (1994) Advances in Social Network Analysis: Research in the Social and Behavioural Science. Sage Publication

Wasserman, S. \& Faust, K. (1994) Social Network Analysis: Methods and Application. New York: Cambridge University Press

Wellings, K., Wadsworth, J., Johnson, A.M., Field, J., Whitaker, L \& Field, B. (1995) Provisions of Sex Education and Early Sexual Experience. The Relation Examined. British Medical Journal, 311 (7002): 417-418

Williams, F., R.E. Rice, \& E.M. Rogers. 1988. Research methods and the new media. New York: Free Press. 
World Youth Report. (2005) World Bank and International Telecommunications Union. World Development Indicator: Washington DC World Health Organisation. (2007) Towards Universal Access: scaling up priority HIVIAIDS intervention in the health sector. Progress Report, April 2007. Geneva: WHO

Worx, W.W. \& Fuseware. 2012. South African Social media landscape 2012. Tech, rep., World Wide and Fuseware, 2012. 